\title{
Implementation of the concept of pedagogical facilitation in the context of sustainable education
}

\author{
Tatyana Zagorulya* \\ Ural State Economic University, 8 Marta Str., 62, 620144 Yekaterinburg, Russia
}

\begin{abstract}
In this article, the author presented the results of a study on the implementation of the concept of pedagogical facilitation in the context of sustainable education. The author of the article described his own experience of work at the university in creating facilitating conditions in the classroom in the discipline «Communication Technologies». The author's concept of pedagogical facilitation is based on the teachings of $\mathrm{K}$. Rogers, in which the main principles are trust, authenticity, unconditional acceptance, intersubjective interaction between students and teachers. In the context of sustainable education, the concept of pedagogical facilitation acquires special significance and value. This is explained by the fact that the principles of sustainable education (relevance, predictability, manufacturability, practicality) correlate with the principles of the concept of pedagogical facilitation. The analysis of the practice-oriented tasks performed by students confirms that the knowledge, abilities, skills, competencies that students master will be in demand both in professional activity and in the life scenario of everyone.
\end{abstract}

\section{Introduction}

In a dynamic, constantly changing world, the main ideas and principles of sustainable education are relevant. The semantic load of the concept of «sustainable» education lies in the reliability and applicability, use of the acquired knowledge, acquired competencies and skills throughout a person's life in the context of lifelong learning, as opposed to «education for life» (Education for a lifetime). Sustainable education through the implementation of the concept of pedagogical facilitation will help achieve sustainable development of the individual and society, be successful in the chosen profession, improve the quality of life and the level of communication between people.

In this article, the author examines the facilitating learning conditions created by the teacher during practical exercises in the discipline «Communication Technologies» both in the classroom and in the situation of distance learning, online, in electronic educational

\footnotetext{
*Corresponding author: tatbor.07@mail.ru
} 
information systems «MS Teams», «Electronic educational resources» (EER). The results of the implementation of the author's concept of pedagogical facilitation, based on the teachings of K. Rogers, are presented in the scientific publications of the author of the article $[1,2,3]$. It should be noted that the experimental work on this issue is continued by the author of the article at the Ural State Economic University (Yekaterinburg). Questions of pedagogical facilitation are solved by both domestic $[4,5]$ and foreign scientists $[6,7,8]$.

\section{Materials and methods}

The purpose of the study is to identify the importance of implementing the concept of pedagogical facilitation in the process of sustainable education.

Research objectives:

- continue experimental work on the implementation of the author's concept of pedagogical facilitation in the context of sustainable education;

- continue to create facilitating conditions for learning in the classroom, contributing to the implementation of the principles of sustainable education;

- to conduct a survey of students, focused on determining the significance and value of the principles of the concept of pedagogical facilitation and sustainable education.

Research methods: theoretical - analysis, synthesis, comparison, generalization; empirical - document analysis; pedagogical observation; self-esteem; experimental work; content analysis.

\section{Results and discussion}

In the course of the study, we came to the conclusion that the ideas and principles of facilitating learning (according to the teachings of K. Rogers) [9, 10] are consonant with the ideas and principles of sustainable education. Facilitating learning and sustainable education are designed to realize the principles of trust, authenticity and unconditional acceptance, as well as freedom to learn. Sustainable education declares progressive ideas and principles for sustainable development of society, opportunities for the formation and self-realization of an individual in a developed civil society. Let us name examples that, in our opinion, correlate with the ideas and principles of facilitating learning: the principle of relevance (the modernity of educational material that incorporates innovations); the principle of predictability (the present is related to the image of the future); the principle of manufacturability (use of information technology); the principle of practicality (application of theory in practice, the ability to solve the needs of people, society), etc. Next, we present the results of the study from the experience of the author of the article on the implementation of the concept of pedagogical facilitation in the context of sustainable education.

The author of the article has developed an electronic educational and methodological complex for the discipline «Communication technologies», which includes the work program of the discipline; lecture materials (presentations, video lectures, brief overview / lecture notes); practice-oriented tasks adapted for online learning with the use of distance technologies (for online seminars and for execution in the EER system (electronic educational resources)); control works for the current certification and intermediate certification of students; students are recommended literature and Internet sources / resources for completing assignments and studying academic disciplines; the criteria for evaluating each task, terms, types of control of the task are determined.The electronic educational and methodological complex for the discipline «Communication technologies» 
is posted on the Portal of electronic educational resources of the university, where students get access to the named materials, have the opportunity to discuss issues in chat with both the teacher and classmates, which is an example of one of the conditions of facilitating learning - intersubjective interaction between teacher and students.

The discipline «Communication technologies» (in the direction of training 38.03.02 Management) is classified as a discipline for choosing a curriculum for training students [11] and is implemented at the Ural State University of Economics (Yekaterinburg). The result of mastering the named discipline is the formation of general cultural competencies in students (the ability to work in a team, tolerantly perceiving social, ethnic, confessional and cultural differences); general professional competencies (the ability to find organizational and managerial decisions and the willingness to take responsibility for them from the standpoint of the social significance of the decisions made); professional competencies (possession of various ways of resolving conflict situations in the design of interpersonal, group and organizational communications based on modern personnel management technologies, including in an intercultural environment).

One of the topics of the practical lesson is «Electronic communications and video technologies». The author of the article has developed the following assignment on this topic for 2 nd year students in the direction of «Management».

The task. Create an Internet group / Internet page on a social network (VKontakte, Facebook, Instagram, etc.) on a specific topic (for example, «Himself a traveler / photographer / cook», «The world of auto / nature / culture / business», «Studying Spanish / Arabic / Latin», «Draw together», «Compose and prosper», «Do it yourself (knitting, embroidery, making bracelets)», etc.). Give a name to your internet group. Place in it relevant materials on the selected topic. Conduct a master class (record audio / video) in the Internet group, get feedback (conduct an express survey of participants). Attract followers / participants (6 and more). Analyze the activities of the created Internet group, identify positive / negative points, offer recommendations for improving the activities of the Internet group.

The facilitating condition of learning is the control and evaluation function as a diagnostic and corrective one, which combines elements of control both from the teacher's side and elements of self-control from the student's side. The results of control and selfcontrol are reflected in spreadsheets of student success, where you can see the progress of each student, the quality of the work performed, since the levels of quality of the assignment are determined: high, medium, low. The following are the assessment criteria and the maximum number of points received by students for the completed assignment: 1 . Creativity, 5 points. 2 . Content, 5 points. 3 . Relevance, 5 points. So, the maximum number is 15 points. To evaluate the work, a student jury ( 3 people) is selected, who view the created groups on social networks: VKontakte, Facebook, Instagram, identify compliance with the named criteria, and give points. For work in the student jury, each referee receives 3 points.

Let us consider examples of the assignment by the students of the 2nd year of the direction of study «Management», full-time education. A team of students (K. Dryga, M. Khofizova, A. Chizhova, E. Kozhevnikova) created the «Culinary Blog» group. The students argued the relevance of the chosen topic by the fact that the independence of a modern person is determined by such a skill as the ability to cook healthy and wholesome food, providing it for themselves and loved ones. The emphasis was on the fact that in the face of a pandemic and self-isolation, people began to develop and improve their skills in cooking. Placement: social network VKontakte.

The main page contains video recipes, explanations to them. The main feature of their group, the students called such an event as the «Gastronomic Tour». A gastronomic tour involves choosing a country (Russia, France, Italy, etc.), studying the culture, national 
cuisine of this country, the most popular recipes for cooking. During the week, for example, recipes of the national cuisine of the selected country are placed in a group.

Then the students carried out an introspection, revealing the positive aspects of their activities: original name; new rubric: gastronomic tour; simple recipes; the opportunity to express your opinion (comments are open); the possibility of «feedback» with the leaders of the group. Among the negative aspects, the team of students attributed the following: the advertising policy is not fully developed; weak connection with subscribers.

The students independently developed recommendations for improving the functioning of the VKontakte group: continuing the gastronomic tour; announcement of a competition for the best design of one dish; development of advertising policy; holding raffles among group members with prizes / souvenirs.

The project for holding the competition was presented in more detail: 1) create a survey on the topic «Attention: competition! Who agrees?!»; 2) select a recipe, invite group subscribers to describe the dish / table setting for the selected recipe; 3) create an album for the purpose of posting the works of participants in the competition; 4) determine the winners of the «likes» competition; 5) awarding the winners; 6) presentation of information about the competition in the group.

The next team of students (Rodionova N., Guseva E., Shaburnikov A., Dudnikova E., Nekrasova A., Akhmetova V.) proposed to create a page on the social network Instagram called «@thai_for_russians», which provides information on learning the Thai language ... The page was created for lovers and connoisseurs of the Thai language, the leading pages help to understand how to pronounce Thai words, in which field of activity the Thai language is in demand. One of the team members (N. Rodionova) held a master class on reading a small dialogue in Thai with translation into Russian. Students posted links and videos of the master class, audio recordings. A team of students conducted a survey of subscribers to the Thai language learning page, analyzed the work of the blog. The students concluded that this topic aroused the interest of subscribers, even those who did not think about learning this language, were also attracted by the profile design made in the same color scheme and the competent presentation of information.

Students noted that subscribers were advised to add introductory lessons (learning the alphabet, adding Russian transcription and accents) in order to better understand the basics of the language; post videos with native speakers. The positive aspects of the functioning of this group: information is presented in an accessible, understandable form; there are no complex combinations of hieroglyphs; available to everyone for basic conversation in Thai with native speakers; design posts in the same style. Negative sides: you need to work out the pronunciation so that someone tells you how to pronounce this or that sound correctly; there is no opportunity to learn how to write and understand written language in Thai; lack of interactivity, lack of the most basic foundations (alphabet, pronunciation rules).

The team has developed recommendations to improve the work of the Instagram page: add the study of the alphabet; rules for combining sounds; post audio / video lessons for the learner to hear pronunciation; change the spelling of words (after each word, place a transcription (in Russian letters)); rules for constructing sentences in Thai; improve the quality of audio / video recording; video tutorials explaining how to write hieroglyphs; to establish «feedback» with students, to carry out interactive interaction.

The following team of students (Mikolenko A., Yuzhakova A.) created an Instagram account: razvivashki_rus. The basis of the team's idea is to make an account a platform for posting various materials on self-development, self-realization and motivation. The topic of self-development is always relevant, each person should strive for development, disclosure of his potential, knowledge of something new.

The students came up with the original name «Pantry of Development» and the motto «Develop with us». The page immediately became popular, subscribers appeared who were 
interested in the posted material: about the leading pages, an announcement of a master class, a master class «Draw Dandelions», two motivational videos (microfilms, including a plot, dialogues, roles), a text post about types of creativity. The team at Insta Stories conducted an express survey of subscribers who rated the content in the profile of the created page.

The student team carried out an introspection, revealed positive aspects: 1) subscribers liked the content (100\% in the polls); 2) managed to attract followers; 3 ) subscribers liked the motivational videos the most; 4) the authors of the project got tremendous pleasure from the work done. Negative sides: 1) master class - too long in time; 2) low volume of audio in the video.

The team developed recommendations for improving the Instagram account «Pantry of Development»: 1) increase the sound volume; 2) to expand the list of conducted master classes, including sketching; 3) increase the speed of master classes, make them faster, more dynamic; 4) attract even more followers / subscribers.

It should be noted that students independently developed master classes, filmed videos, motivational microfilms, created step-by-step instructions, came up with the design of their groups on social networks, and compiled questionnaires for interviewing group members. The student jury studied the content and functioning of the groups / pages on VKontakte and Instagram created by the students, assessed according to the specified criteria: creativity, meaningfulness, relevance. The referees determined the best team: «Pantry of Development» (Instagram page, authors - students A. Mikolenko, A. Yuzhakova).

Analyzing the activities of student teams, the teacher noted the high level of task performance and pronounced personality traits: independence, creativity, responsibility, reflection, critical thinking.

We have received «feedback» from students who have chosen the course «Communication Technologies». Conducting a survey, the teacher asked the students to name the positive and negative aspects, what they liked / disliked in the course «Communication Technologies» (28 people took part in the survey, 2nd year students of the direction of study «Management» of full-time education). Students highly appreciated the efforts of the teacher who implemented the course «Communication Technologies» within the framework of the author's concept of pedagogical facilitation; moreover, in the context of a pandemic, the course was conducted remotely in electronic educational information systems «MS Teams», «Electronic educational resources» (EER).

Anastasia M.: «Thank you very much for the course, I really liked it! I constantly told my mother about our couples that I like them the most! I am very glad that I made the right decision in the 1st year and chose communication technologies! There are a lot of advantages, but I will focus on those that are now in my memory: 1) A LOT of interactivity, and it's so great! I love it when they combine theory with something interesting; 2) I really liked the couple with children's photos; 3) today's game left a lot of impressions, especially how the guys and I in the conversation were creative about a tie and wrote a poem; 4) interesting seminars - they gave the opportunity to be even more creative, and also to learn something new! 5) as always, the student jury is on top - it's very nice to hear feedback from the guys! 6) presentation of theoretical material - a combination of videos, life examples, reading by O. Henry. As for the minuses, I can hardly single them out, except perhaps - the situation in the country, because of which we could not meet in person and communicate. Suggestions: to conduct some couple in the form of a «brainstorm» or «quiz, pliz» on the course material and on the knowledge of general facts, I think it will be very fun and informative if held at the university»!

Karina E.: «All lectures are very interesting, a lot of interactive. The most interesting lectures among all distance lectures. Very interesting and useful seminar assignments that taught me a lot. There are no downsides. Thanks you»! 
Christina D.: «I liked the variety of training options offered, interesting, relevant information, an unusual format for analyzing films, and today's game».

Mavzuna H.: «I especially liked playing in teams and creating my own blog. The most productive, creative and fun lectures. Practices, on which we put all our creativity and knowledge, and also revealed new talents in ourselves. I agree that it is a pity, we did not get together, it would be a little more atmospheric, although much more».

Daria V.: «Everything is gorgeous, the possibility of self-expression, full information in the lectures. It's just a pity that there is no live personal contact».

Anastasia A.: «The course was informative and interesting, there was a lot of communication between students and students and the teacher. I liked the seminar assignments, especially the analysis of films and the preparation of a mini-training. The last lecture was very interesting and funny. There are no downsides for me. Thanks for the course».

Andrey Sh.: «Pros: it was interesting, a lot of interactive, you won't get bored».

The results of the survey showed that students are interested in obtaining and using relevant theoretical information, independent consideration and presentation of tasks of a practice-oriented nature, which indicates a high level of responsibility, motivation for learning, mastering competencies and skills. The teacher who creates facilitating learning conditions acts both as a facilitator and as a game technician, which allows you to build subject-subject relationships in the educational process [12].

\section{Conclusions}

We believe that the implementation of the concept of pedagogical facilitation in the process of sustainable education is significant and effective, contributes not only to the development of students' skills and abilities, but also helps to determine the value orientations, the life position of everyone.

The tasks of the research have been completed: experimental work continued on the implementation of the author's concept of pedagogical facilitation in the context of sustainable education (in this article, the author presents his own work experience). Facilitating conditions for learning in the classroom have been created that correspond to the principles of sustainable education (for example, relevance, predictability, manufacturability, practicality, internationality). A survey of students was carried out, the results of which confirmed the significance and value of the principles of the concept of pedagogical facilitation and sustainable education.

The implementation of the author's concept of pedagogical facilitation in the context of sustainable education creates optimal conditions for unlocking the potential of students, for creative self-realization of students in a situation of freedom of learning, personal choice (the course «Communication technologies» is an optional discipline). It should be noted that the knowledge, skills, competencies acquired by students will be in demand in their future professional activities, in various life situations.

\section{References}

1. A.Yu. Ryabtsev, T.V. Kochergina, T.B. Zagorulya, Modern problems of science and education, 4 (2019)

2. T.B. Zagorulya, Scientific journal «Scientific opinion», 3 (2020)

3. T.B. Zagorulya, International Scientific Conference «Digitalization of Education: History, Trends and Prospects», 437 (2020)

4. M.N. Dudina, Higher School Didactics: From Traditions to Innovations (2015) 
5. R.V. Ovcharova, Psychological Facilitation of the Work of a School Teacher (2007)

6. B. Rienties, N. Brouwer, S. Lygo-Baker, Teaching and Teacher Education, 29 (2013)

7. A.Y.N. Cheng, E. Szeto, Teaching and Teacher Education, 58 (2016)

8. J. Fowler, Nurse Education Today, 28 (2008)

9. C. R. Rogers, Freedom to learn for the 80s (1982)

10. C. R. Rogers, Client-Centered therapy: its current practice implications a. theory (1991)

11. T.B. Zagorulya, Working program of the discipline «Communication technologies», Portal of electronic educational resources of USUE (2020)

12. T.B. Zagorulya, Humanitarian scientific bulletin, 2 (2020) 